7. Aydemir D, Ulusu NN. Is glucose-6-phosphate dehy (COVID-19) infections and deaths? Pathog Glob Health. 2020; 114:109-10. https:/ / doi.org/10.1080/20477724.2020.1751388

8. Kassi EN, Papavassiliou KA, Papavassiliou AG. G6PD and chloroquine: selecting the treatment against SARS-CoV-2? J Cell Mol Med. 2020;24:4913-4. https:/ / doi.org/10.1111/ jcmm.15312

9. Wu YH, Tseng CP, Cheng ML, Ho HY, Shih SR, Chiu DT. Glucose-6-phosphate dehydrogenase deficiency enhances human coronavirus 229E infection. J Infect Dis. 2008; 197:812-6. https://doi.org/10.1086/528377

10. Delgado-Roche L, Mesta F. Oxidative stress as key player in severe acute respiratory syndrome coronavirus (SARS-CoV) infection. Arch Med Res. 2020. Apr 30 [Epub ahead of print]. https://doi.org/10/1016/j.arcmed.2020.04.019.

Address for correspondence: Kieran Palmer, Renal Department, King's College Hospital National Health Service Foundation Trust, Denmark Hill, Brixton, London SE59RS, UK; email: kieran. palmer3@nhs.net

\section{Asymptomatic SARS-CoV-2 Infection in Nursing Homes, Barcelona, Spain, April 2020}

\author{
Blanca Borras-Bermejo, ${ }^{1}$ Xavier Martínez-Gómez, ${ }^{1}$ \\ María Gutierrez-San Miguel, Juliana Esperalba, \\ Andrés Antón, Elisabet Martin, Marta Selvi, \\ María José Abadías, Antonio Román, \\ Tomàs Pumarola, Magda Campins, Benito Almirante \\ Author affiliations: Vall d'Hebron Hospital Universitari, Barcelona, \\ Spain (B. Borras-Bermejo, X. Martínez-Gómez, M. Gutierrez-San \\ Miguel, J. Esperalba, A. Antón, M.J. Abadías, A. Román, \\ T. Pumarola, M. Campins, B. Almirante); Universitat Autònoma de \\ Barcelona, Bellaterra, Spain (X. Martínez-Gómez, A. Antón, \\ A. Román, T. Pumarola, M. Campins, B. Almirante); Servei Atenció \\ Primària Muntanya, Barcelona (E. Martin); Centre d'Atenció Primària \\ Sant Andreu, Barcelona (M. Selvi)
}

DOI: https://doi.org/10.3201/eid2609.202603

During the coronavirus disease pandemic in Spain, from April 10-24, 2020, a total of 5,869 persons were screened for severe acute respiratory syndrome coronavirus 2 at nursing homes. Among residents, 768 (23.9\%) tested positive; among staff, $403(15.2 \%)$. Of those testing positive, $69.7 \%$ of residents and $55.8 \%$ of staff were asymptomatic. s of April 2020, Spain was one of the countries accounting for the most coronavirus disease (COVID-19) deaths (1). More than half of those deaths occur in persons $>80$ years of age (2), which highlights the vulnerability of the elderly. Moreover, severe acute respiratory syndrome coronavirus 2 (SARS-CoV-2) can be easily spread within nursing homes, causing outbreaks with high associated mortality rate $(3,4)$. By the beginning of April, the exponential increase of cases overwhelmed the healthcare system in Spain. In this context, rapid outbreak identification and early intervention in nursing homes was needed.

At Vall d'Hebron Hospital, a tertiary hospital in Catalonia, Spain, we conducted test-based screening as a containment measure to promptly implement effective prevention and control measures in nursing homes. We present the early results of a coordinated intervention with primary care teams in $\approx 6,000$ residents and facility staff in nursing homes in our catchment area.

We evaluated 69 nursing homes that had a total census of 6,714 persons. We excluded previous laboratory-confirmed cases of COVID-19. During April 10-24, an integrated team of hospital and primary care staff obtained samples for SARS-CoV-2 testing from all residents and workers: nasopharyngeal and oropharyngeal swab samples both combined in the same collection tube with viral transport media. We used a commercial CE-IVD-marked, real-time reverse transcription PCR-based assay (Cobas SARSCoV-2; Roche Diagnostics, https:/ / www.roche.com) on a Cobas 6800 system.

Each nursing home director recorded any symptoms present at least 48 hours before the scheduled day of testing for all residents and staff. According to the World Health Organization case definition of a suspected case of COVID-19, a person was classified as symptomatic if fever or acute respiratory symptoms were present at any moment during the preceding 14 days. In the absence of either, the person was considered to be asymptomatic.

We obtained a total of 5,869 samples, 3,214 from residents and 2,655 from facility staff. Overall, 768 $(23.9 \%)$ residents and $403(15.2 \%)$ staff members tested positive for SARS-CoV-2 (Table). The presence of fever or respiratory symptoms during the preceding 14 days was recorded in 2,624 residents (81.6\%) and 1,772 staff members $(66.7 \%)$. Among those testing positive and for whom we had information about symptoms, $69.7 \%$ of the residents and $55.8 \%$ of staff were asymptomatic.

${ }^{1}$ These first authors contributed equally to this article. 
Table. SARS-CoV-2 test results for residents and staff of 69 nursing homes, Barcelona, Spain, April 2020*

Patient status during the preceding 14 days

Asymptomatic

Symptomaticł

${ }^{*}$ Results include all residents and staff who were in severe acute respiratory syndrome coronavirus 2 .

†Percentage calculated over those with symptom information available; it was missing for $590(18.4 \%)$ residents and $883(33.3 \%)$ staff members. $\ddagger A$ person was considered symptomatic if fever or respiratory symptoms were present at time of assessment, or at any moment in the preceding 14 days.

On the basis of laboratory results, we planned specific infection prevention and control measures, adapted to facility characteristics in $<72$ hours. The most relevant measures applied included isolation of infected residents, establishing cohorted areas and designated staff, excluding infected staff from work, ensuring proper supply of personal protection equipment, and training staff about contact- and droplet-based precautions. We established coordinated follow-up evaluation with primary care teams and facility directors.

COVID-19 heavily affected nursing homes, causing uncountable deaths in Spain $(5,6)$. Restriction policies for visitors in nursing homes were described as part of the state of emergency declared on March 14 (7), but a national guideline to reduce the risk for SARS-CoV-2 transmission in these settings was not available until March 24 (8). Moreover, despite knowledge of community transmission starting in late February, widespread testing for SARS-CoV-2 was not available until mid-April.

Our data show an overall high prevalence of SARS-CoV-2 infection in residents and staff, noting a high transmission in these settings. Specific aspects of nursing homes (shared rooms or bathrooms, physically or cognitively impaired residents requiring high-demand care, rotating staff working in different facilities) and a limited adoption of prevention and control measures as reported by our teams are some factors that may explain these results. Among those with known symptom status, we found a high proportion of asymptomatic cases: $69.7 \%$ of infected residents and $55.8 \%$ of infected staff.

Our study had several limitations. The ascertainment process could lead to misclassification due to atypical symptoms in the elderly. Furthermore, crosssectional symptom assessment and testing did not allow us to differentiate between presymptomatic and asymptomatic cases. Nevertheless, these values are consistent with a study performed in a nursing facility in King County, Washington, USA, in which 56\% of the residents testing positive were asymptomatic (9).

Given that presymptomatic and asymptomatic transmission has been demonstrated (10), our data suggest that asymptomatic cases could have had an important role in transmission dynamics. Symptoms-based approaches would have failed to correctly identify cases and therefore continued transmission. Furthermore, testing of facility staff should be included as part of the prevention and control measures, because they may contribute to sustained transmission.

In conclusion, the high prevalence of SARSCoV-2 cases found in nursing homes highlights that this vulnerable population requires special attention and proactive interventions in coordination with the primary care teams. In the context of established community transmission of SARS-CoV-2, we recommend implementing test-based screening irrespective of symptomatology in nursing homes as the best approach to rapidly implement prevention and control measures.

\section{Acknowledgments}

We thank the Preventive Medicine and Epidemiology Department, Microbiology Department, and primary care teams, along with nursing home directors and staff, who actively collaborated in the implementation in a tight timeframe. We thank Friedel Laaf for the language review.

\section{About the Author}

Dr. Borras-Bermejo is a preventive medicine and public health physician working in the Preventive Medicine and Epidemiology Department in Vall d'Hebron University Hospital, Barcelona, Spain. Her research interests include vaccines and hospital infection prevention and control.

\section{References}

1. World Health Organization. Coronavirus disease (COVID-19) situation report 106. 2020 [cited 2020 June 4]. https://www.who.int/emergencies/diseases/novelcoronavirus-2019/situation-reports

2. Centro de Coordinación de Alertas y Emergencias Sanitarias. Dirección General de Salud Pública, Calidad e Innovación. Update 108. Coronavirus disease (COVID-19) [in Spanish]. 2020 May 17 [cited 2020 May 21]. https://bit.ly/2Ajvtt2

3. Comas-Herrera A, Zalakain J. Mortality associated with COVID-19 outbreaks in care homes: early international evidence. 2020 [cited 2020 May 21]. https://ltccovid.org/ 
2020/04/12/mortality-associated-with-covid-19outbreaks-in-care-homes-early-international-evidence

4. Etard J-F, Vanhems P, Atlani-Duault L, Ecochard R. Potential lethal outbreak of coronavirus disease (COVID-19) among the elderly in retirement homes and long-term facilities, France, March 2020. Euro Surveill. 2020;25:8-10. https:/ / doi.org/10.2807/1560-7917.ES.2020.25.15.2000448

5. Rada AG. Covid-19: the precarious position of Spain's nursing homes. BMJ. 2020;369:m1554. https://doi.org/ 10.1136/bmj.m1554

6. ECDC Public Health Emergency Team, Danis K, Fonteneau L, Georges S, Daniau C, Bernard Stoecklin S, et al. High impact of COVID-19 in long-term care facilities, suggestion for monitoring in the EU/EEA, May 2020. Euro Surveill. 2020;25:1-5. https:// doi.org/10.2807/1560-7917. ES.2020.25.22.2000956

7. Ministerio de la Presidencia relaciones con las cortes y memoria democrática. Royal Decree 463/2020 (March 14) declaring the alarm state for the health crisis management situation caused by COVID-19. BOE no 67 from March 14, 2020 [in Spanish]. 2020 Mar 14;67(I):25390-400 [cited 2020 May 21]. https://www.boe.es/diario_boe/txt.php?id= BOE-A-2020-3692

8. Ministerio de Sanidad. Guideline for the prevention and control of COVID-19 in nursing homes and other residential social services [in Spanish]. 2020 [cited 2020 May 21]. https://www.mscbs.gob.es/profesionales/ saludPublica/ccayes/alertasActual/nCov-China/ documentos/Residencias_y_centros_sociosanitarios_ COVID-19.pdf

9. Arons MM, Hatfield KM, Reddy SC, Kimball A, James A, Jacobs JR, et al.; Public Health-Seattle and King County and CDC COVID-19 Investigation Team. Presymptomatic SARS-CoV-2 infections and transmission in a skilled nursing facility. N Engl J Med. 2020;382:2081-90. https:/ / doi.org/10.1056/NEJMoa2008457

10. He X, Lau EHY, Wu P, Deng X, Wang J, Hao X, et al. Temporal dynamics in viral shedding and transmissibility of COVID-19. Nat Med. 2020;26:672-5. https:/ / doi.org/ $10.1038 / \mathrm{s} 41591-020-0869-5$

Address for correspondence: Magda Campins, Servei de Medicina Preventiva i Epidemiologia, Vall d'Hebron Hospital Universitari, Vall d'Hebron Barcelona Hospital Campus, Passeig Vall d'Hebron 119-129, 08035 Barcelona, Spain; email: mcampins@vhebron.net

\section{Leuconostoc lactis and Staphylococcus nepalensis Bacteremia, Japan}

\author{
Satoshi Hosoya, Satoshi Kutsuna, Daisuke Shiojiri, \\ Saeko Tamura, Erina Isaka, Yuji Wakimoto, \\ Hidetoshi Nomoto, Norio Ohmagari
}

Author affiliation: National Center for Global Health and Medicine, Tokyo, Japan

DOI: https://doi.org/10.3201/eid2609.191123

Leuconostoc lactis is a glycopeptide-resistant, grampositive, facultative anaerobic coccus isolated from dairy products, whereas Staphylococcus nepalensis is coagulase-negative coccus that has not been identified as human pathogen. We report an instructive case of $L$. lactis and $S$. nepalensis bacteremia in a 71-year-old man who experienced Boerhaave syndrome after a meal.

Teuconostoc lactis is an intrinsically glycopeptide-reListant but ampicillin-susceptible, gram-positive, facultative anaerobic coccus (1) found in food products including dairy products, vegetables, and wine. L. lactis is a very rare pathogen associated with bloodstream infections (2). Staphylococcus nepalensis is a novobiocin-resistant coagulase-negative staphylococcus also found in food products, such as dry-cured ham and fish sauce, that has not been reported as a human pathogen (3-5). Neither L. lactis nor S. nepalensis is part of normal human bacterial flora $(2,3)$.

A 71-year-old man with hypertension and hyperlipidemia sought care for upper abdominal pain and vomiting after a meal at his son's restaurant. A computed tomography (CT) scan showed collapse of the lower esophagus wall and expansion of the mediastinum; medical staff diagnosed a spontaneous esophageal rupture and performed emergency surgery. Surgical findings demonstrated a $5 \mathrm{~cm}$ perforation of the lower esophagus with no rupture to the thoracic and abdominal cavity. The final diagnosis included Boerhaave syndrome, esophageal hiatus hernia, and mediastinitis. Two sets of blood culture taken on day 1 were positive for gram-positive cocci, which we identified by matrix-assisted laser desorption/ionization time-of-flight (MALDI-TOF) mass spectrometry as L. lactis in an aerobic bottle $(10.7 \mathrm{~h}$ to culture) and an anaerobic bottle (13.3 h to culture) and S. nepalensis in 1 anaerobic bottle $(24.3 \mathrm{~h}$ to culture). The 2 bacteria were indications of true bacteremia; therefore, we escalated ampicillin/sulbactam (treatment to piperacillin/tazobactam for L. lactis (Appendix Table 1, https://wwwnc.cdc.gov/EID/ 